\title{
Control-oriented model of a membrane humidifier for fuel cell applications
}

\author{
Miguel Solsona ${ }^{\mathrm{a}, *}$, Cristian Kunusch $^{\mathrm{b}}$, Carlos Ocampo-Martinez $^{\mathrm{c}}$ \\ ${ }^{a}$ BIOS-Lab on a Chip Group, MESA+ Institute for Nanotechnology and MIRA Institute for Biomedical Technology and Technical Medicine, \\ University of Twente, 7500 AE Enschede, The Netherlands \\ ${ }^{b}$ Brose Fahrzeugteile GmbH, Ohmstraße 2a, D-97076 Würzburg, Germany \\ ${ }^{c}$ Universitat Poliètcnica de Catalunya, Institut de Robòtica i Informàtica Industrial (CSIC-UPC), Llorens i Artigas, 4-6, 08028 Barcelona, Spain
}

\begin{abstract}
Improving the humidification of polymer electrolyte membrane fuel-cells (PEMFC) is essential to optimize its performance and stability. Therefore, this paper presents an experimentally validated model of a low temperature PEMFC cathode humidifier for control/observation design purposes. A multi-input/multi-output non-linear fourth order model is derived, based on the mass and heat dynamics of circulating air. In order to validate the proposed model and methodology, experimental results are provided. Finally, a non-linear control strategy based on second order sliding mode is designed and analysed in order to show suitability and usefulness of the approach.
\end{abstract}

Keywords: PEM fuel-cell, gas humidifier, modelling, control-oriented model

\section{Introduction}

Fuel cells are electrochemical devices that convert chemical energy into electricity. In particular, polymer electrolyte membrane fuel cells (PEMFC) use hydrogen and oxygen to produce electrical energy, heat and water, at high efficiency [1] [2] [3]. The purpose of gas humidifiers is to maintain the inlet gases of the fuel cell at optimal moisture and temperature. Moreover, an excess or shortage of water reduces considerably the fuel-cell performance [4] [5] [6].

There exist two types of humidification systems for PEMFC, namely internal and external. Among the internal humidification systems there are stack-integrated membrane humidifiers, steam or liquid water injection humidifiers, and membrane additives and porous absorbent sponges. The principal disadvantage of internal humidification is the limit of the total cathode outlet water available, determined by the fuel-cell conditions, especially at higher flow rates [7] [8] [9] [10] [11] [12] [13].

External humidification provides more flexibility to adjust the optimal moisture and temperature of the reactant gases, although extra energy is needed. There are several external humidification systems, being all of them based on physical contact between water and air. The most common systems are: the saturated bubbler, the enthalpy wheel exchanger and the permeable membrane. Saturated bubbler humidifiers reduce the control of the gas moisture and cause an extra pressure drop in the gas channel, [14]. In order to avoid this effect, [15] combined a saturated bubblier and a vapor injector in order to have a better control of the humidification. Enthalpy wheel exchanger humidifiers are known to be much complicated and expensive devices, more suitable for large PEMFC systems [16]. However,

\footnotetext{
${ }^{*}$ Corresponding author:

Email address: m.solsona@utwente.nl (Miguel Solsona)
} 
permeable membrane humidifiers are simple and inexpensive devices, enough reasons to be the most popular devices in low temperature PEMFC systems. Permeable-membrane humidifiers put in contact dry gas and saturated vapour or deionized water, either in cross or counter flows. Commonly, the membranes used in these devices are made of Nafion. However, in order to reduce the costs of the humidifiers and increase the water injection to the cathode gases, some approaches to find new materials for membranes have been done. Besides, [17] and [12] studied different membranes materials and concluded good properties compared to the Nafion membranes. Regarding the transport phenomena, [18], [19] and [20] studied the gas-to-gas contact membrane humidifiers concluding that reducing the dry gas flow rate that enters the humidifier, increases the outlet gas dew point. On the other hand, [21], [22], [23] and [24] studied the gas-to-water membrane humidifiers enabling a better control and higher dew points at higher flow rates. Hence, the gas-to-water membrane humidifier is more suitable to be used in PEMFC systems [25].

One of the main challenges faced when using a gas humidification system is related to the proper management of its dynamics facing the proper control of the related variables of the whole process. In this sense, a proper regulation of gas or water flows, as well as the suitable manipulation of the power related to the warming temperature, make the entire PEMFC process more efficient, accurate and stable. To this end, knowing the way the humidification system behaves and how its internal dynamics reacts, when facing different changes of its constitutive variables, allows better design of control strategies and reaching improved performances. This knowledge can only be consolidated by means of developing a systematic approach for modeling humidification processes for control oriented tasks in fuel-cell systems.

In this context, two main contributions can be clearly highlighted in the current research manuscript. Firstly, the paper is focused on the development and experimental validation of a control-oriented dynamical model of the air humidification subsystem of a PEMFC cathode line. The control-oriented nature of the model relies on the fact that a deeply detailed knowledge of the system dynamics is not fully necessary when the humidification device is integrated into a closed-loop scheme, since the feedback control topology allows to maintain a suitable trade off between accuracy and complexity, avoiding the exact determination of certain dynamical behaviours difficult to identify and model. Secondly, the obtained model is properly validated by using real data obtained from a humidification system installed in a test bench located at the Fuel Cells Lab of the Technical University of Catalonia (BarcelonaTech). The validation tests allow showing the suitability of the proposed model and methodology. Finally, in order to better present the effectiveness of the proposed dynamical model for control design tasks, simulations tests were conducted using a closed-loop strategy based on the so-called Super-Twisting control algorithm.

The humidification system analysed in this paper is a Nafion ${ }^{\circledR}$ membrane external humidification device based on stationary deionized liquid water, where the air passes through permeable tubes inside a container full of deionized water. The approach is similar to [23], but the improvement is focused on reducing the parasitic energy loses by avoiding to pump the deionized water and having a better control of the relative humidity and temperature of the humidifier outlet gas.

The remainder of the paper is organized as follows. Section II deeply describes the model of the gas humidifier, which is divided into two parts: mass and energy balances. Section III presents and discusses the experimental results of the real validation of the proposed dynamical model with respect to data obtained from experimental tests. Given the control-oriented natured of the proposed model, Section IV introduces a control strategy based on the SuperTwisting algorithm and shows, in a simulation environment, the performance of the proposed model facing relative humidity regulation tasks. Finally, the main conclusions are summarized in Section V.

\section{Air humidifier model}

The operating principle of the membrane humidifiers is to feed deionized water into the gas by means of diffusion. The level of humidification is defined by the water amount transferred across the polymeric membrane and the initial vapor contained in the ambient air. The relative humidity is then defined as

$$
\begin{aligned}
R H & =\frac{P_{v}}{P_{\text {Sat }}}, \\
R H_{\text {hum }} & =\frac{P_{v, a m b}+P_{\text {inj }}}{P_{\text {Sat }}},
\end{aligned}
$$




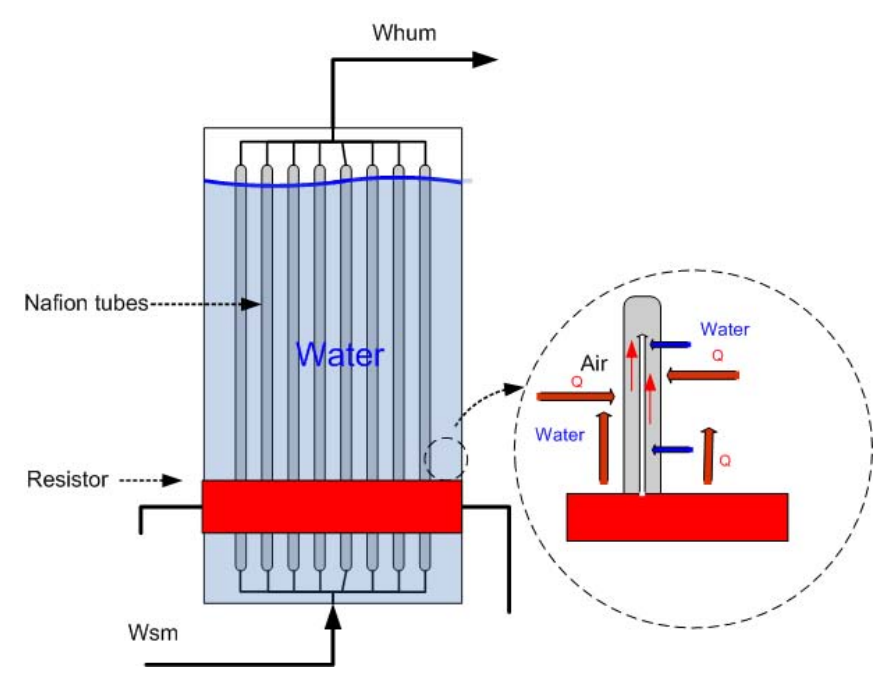

Figure 1. Heat and mass transport sketch

where $R H$ is a general definition of relative humidity, $R H_{c a}$ is the relative humidity at the fuel-cell cathode, $P_{v}(\mathrm{~Pa})$ is the vapor pressure, $P_{v, a m b}(\mathrm{~Pa})$ is the ambient vapor pressure, $P_{i n j}$ is the injected vapor pressure and $P_{\text {sat }}(\mathrm{Pa})$ is the saturation pressure of air.

There are relevant processes in the system. First of all, as seen in Fig. 1, the gas flows through tubes located in a container full of stationary deionized water. Part of this water crosses the membrane by diffusion and, therefore, there is a mass transfer from the water to the air through the Nafion ${ }^{\circledR}$ membranes. This flow causes a mass/pressure dynamics inside the tubes, greatly influenced by the temperature of the water. Finally, the stationary water is heated by an electrical resistor and cooled by various processes: the mass and heat transfers to the air, the phase change and the heat leaks. Water is automatically refilled from a external container by using a pump. Before deriving the governing equations, the following assumptions were made:

- The air is treated as an ideal gas.

- The kinetic and potential energies are considered negligible.

- The vapor transport through the tubes is constant along its length but not over time.

- There are not chemical reactions in the system and the densities of gases and water are considered constant.

The model development is split into two parts: the mass dynamics and the temperature dynamics.

\subsection{Mass dynamics}

The gas enters the humidifier at a slightly higher pressure than atmospheric pressure due to an air compressor. Besides, a supply manifold is placed between the compressor and the humidifier. In order to have a clear view of the system, the inlet flow is separated into dry air and vapor, which are mathematically expressed as follows:

$$
\begin{aligned}
W_{d r y, s m} & =\frac{W_{a i r, s m}}{1+\omega_{d r y, a i r}}, \\
W_{v, s m} & =W_{s m}-W_{d r y, s m}, \\
\omega_{d r y, a i r} & =\frac{G_{v}}{G_{a}} \frac{P_{s a t} R H_{a m b}}{P_{a m b}-P_{s a t} R H_{a m b}},
\end{aligned}
$$

where subindices $s m$ and hum represent the inlet (supply manifold) and outlet (humidifier), respectively, $P_{a m b}$ is the ambient pressure, $R H_{a m b}$ is the ambient relative humidity, $G_{v}$ and $G_{a}$ are the molar masses of water and air $\left(\mathrm{mol} \mathrm{kg}^{-1}\right)$, 
$\omega_{d r y, a i r}$ is the inlet dry air ratio, $W_{d r y, s m}$ is the inlet mass flow of dry air $\left(\mathrm{kg} \mathrm{s}^{-1}\right), W_{v, s m}$ is the inlet mass flow of vapor $\left(\mathrm{kg} \mathrm{s}^{-1}\right)$ and the $W_{\text {air,sm }}$ is the total inlet mass flow of air $\left(\mathrm{kg} \mathrm{s}^{-1}\right)$. Notice that (2a) corresponds with the dry air while (2b) denotes the vapor. One of the most important variables to be analyzed is the vapor injected to the air flow $W_{i n j}$, which can be expressed as

$$
W_{v, \text { inj }}=D_{m e m} \frac{S_{w}-S_{a}}{h_{m}} G_{v} A,
$$

where $D_{m e m}$ is the diffusion coefficient of the water in air $\left(\mathrm{m}^{2} \mathrm{~s}^{-1}\right), h_{m}$ is the thickness of the membrane (m) and $A$ $\left(\mathrm{m}^{2}\right)$ is the area of contact between the water and the membrane. Moreover, $S_{w}$ and $S_{a}$ are the water concentrations on both sides of the tube membrane, water and air respectively, which are expressed as

$$
\begin{gathered}
S_{a}=\frac{\rho_{m, d r y}}{G_{m e m}} \alpha_{a}, \\
S_{w}=\frac{\rho_{m, s d r y}}{G_{m e m}} \alpha_{w},
\end{gathered}
$$

where $\rho_{m, d r y}$ is the dry membrane density $\left(\mathrm{kg} \mathrm{m}^{-3}\right), G_{m e m}$ the molar mass of the membrane $\left(\mathrm{kg} \mathrm{mol}^{-1}\right)$ and $\alpha$ is the water content on the considered side of the membrane that only depends on the $R H$ as follows [27]:

$$
\alpha_{a}=\left(0.043+17.81 R H-39.85 R H^{2}+36 R H^{3}\right) .
$$

Besides, [26] reports that $\alpha_{w}$, on the water side of the membrane, varies within the range between 14 and 22 . It is 14 when the membrane is in equilibrium with saturated vapor and 22 when it is in equilibrium with liquid water. In this study, this value is assumed to be 22 due to the high operating temperature of the liquid water. The mass transference coefficient $D_{\text {mem }}$ is defined in [27] as

$$
D_{m e m}=D_{\alpha}^{\Phi}
$$

where $\Phi=E_{0}\left(\frac{1}{303}-\frac{1}{T}\right)$ and $D_{\alpha}$ is defined as [3]

$$
D_{\alpha}=\left\{\begin{array}{lll}
10^{-1} & \text { if } \quad \alpha_{\text {mem }}<2 \\
\left(1+2\left(\alpha_{\text {mem }}-2\right)\right) \times 10^{-6} & \text { if } \quad 2 \leq \alpha_{\text {mem }} \leq 3 \\
\left(3-1.67\left(\alpha_{m e m}-3\right)\right) \times 10^{-6} & \text { if } 3<\alpha_{\text {mem }}<4.5 \\
1.25 \times 10^{-6} & \text { if } 4.5 \leq \alpha_{\text {mem }}
\end{array}\right.
$$

being $E_{0}\left(\mathrm{~J} \mathrm{~mol}^{-1}\right)$ the water molecule activation energy and $T(\mathrm{~K})$ the membrane temperature that is assumed to be the same as the temperature of the water. To simplify the notation, Appendix describes the $3^{r d}$ option of (8). Likewise, $D_{\alpha}$ has a piecewise form that is dependent on $\alpha_{m e m}$, which is the water quantity inside the membrane and is defined as (6) but, in this case, the $R H_{m}$ becomes

$$
R H_{m}=\frac{R H_{h u m}+R H_{w}}{2},
$$

where $R H_{\text {hum }}$ and $R H_{w}$ are the relative humidities on the air and water sides of the membrane, respectively. At this point, the air mass dynamics can be defined as

$$
\begin{aligned}
\frac{m_{d r y}}{d t} & =\left(W_{d r y, s m}-W_{d r y, h u m}\right), \\
\frac{m_{v}}{d t} & =\left(W_{v, s m}-W_{v, h u m}+W_{v, \text { inj }}\right) .
\end{aligned}
$$

The gas outlet $\left(W_{v, \text { hum }}+W_{d r y, \text { hum }}\right)$ is defined by a nozzle equation obtained experimentally. This relationship is a linear function strongly dependent on the cathode pressure and the cathode pressure drop. It could be approximated by a bivariate function, obtained through experimental data gathered from tests performed at various operating pressures, i.e.,

$$
\begin{aligned}
W_{\text {hum }} & =f\left(P_{c a}, P_{\text {hum }, \text { diff } f}\right), \\
P_{\text {hum }, \text { diff }} & =P_{\text {hum }}-P_{c a},
\end{aligned}
$$


where $P_{c a}(\mathrm{~Pa})$ is the cathode's pressure, $P_{\text {hum diff }}(\mathrm{Pa})$ the pressure difference inside the humidifier and $P_{\text {hum }}(\mathrm{Pa})$ the pressure inside the humidifier. Due to its dependence on temperature, there is a need to convert the mass dynamics into pressure by the equation of ideal gases as follows:

$$
\begin{aligned}
\frac{d P_{d r y, a i r}}{d t} & =\frac{R_{a}}{V_{\text {hum }}}\left(m_{d r y, s m} T_{\text {sm }}-m_{d r y, \text { hum }} T_{\text {hum }}\right), \\
\frac{d P_{v}}{d t} & =\frac{R_{v}}{V_{\text {hum }}}\left(m_{v, s m} T_{s m}-\left(m_{v, \text { hum }}-m_{v, \text { in } j}\right) T_{\text {hum }}\right),
\end{aligned}
$$

where $R_{a}\left(\mathrm{~N} \mathrm{~m} \mathrm{~kg}^{-1} \mathrm{~K}^{-1}\right)$ and $R_{v}\left(\mathrm{~N} \mathrm{~m} \mathrm{~kg}^{-1} \mathrm{~K}^{-1}\right)$ are the specific gas constants of dry air and vapor respectively, $T_{s m}$ $(\mathrm{K})$ and $T_{\text {hum }}(\mathrm{K})$ are inlet flow temperature and the humidifier gas temperatures.

\subsection{Heat dynamics}

\subsubsection{Water}

It is considered that the water mass is constant over time and the water temperature is homogeneous within the entire container. The heat flows are: the electrical power transferred from the resistance to the water $P w$, the heat transmission from the water to the air by convection $Q_{C V}$, the change of phase due to vapour formation $Q_{F O R}$ and the heat losses $Q_{L O S S}$ (see Fig. 1). This process causes a heat dynamics given by the following differential equations:

$$
\begin{aligned}
m_{w} \frac{h_{w}}{d t} & =P w-W_{i n j} H-Q_{F O R}-Q_{C V}-Q_{L O S S}, \\
m_{w} C p_{w} \frac{T_{w}}{d t} & =V I-W_{i n j} H-W_{i n j} \lambda-U A_{m}\left(T_{w}-T_{a i r}\right)-U A_{w}\left(T_{w}-T_{a m b}\right),
\end{aligned}
$$

where $m_{w}(\mathrm{~kg})$ and $C p_{w}\left(\mathrm{~J} \mathrm{~kg}^{-1} \mathrm{~K}^{-1}\right)$ are the mass and heat capacity of water respectively, $V(\mathrm{~V})$ and $I(\mathrm{~A})$ are the voltage across and current through of the electrical resistance, $T_{w}(\mathrm{~K}), T_{a i r}(\mathrm{~K})$ and $T_{a m b}(\mathrm{~K})$ are the water, air and ambient temperatures, $\lambda\left(\mathrm{J} \mathrm{kg}^{-1}\right)$ is the heat of vapor formation, $U A_{m}\left(\mathrm{~J} \mathrm{~K}^{-1}\right)$ and $U A_{w}\left(\mathrm{~J} \mathrm{~K}^{-1}\right)$ are the general coefficients of heat transmission and the areas of the membrane and the container material respectively.

\subsubsection{Air}

As presented before, the humidity is defined by $P_{V}(\mathrm{~Pa})$ and $P_{\text {sat }}(\mathrm{Pa})$, both of which are dependent on the temperature. The gas is separated into two parts -dry air and vapor- as done previously. The equations of the air and vapour are given by the following expressions:

\section{Dry air}

$$
\frac{m_{d r y}}{d t} U_{d r y}+m_{d r y} \frac{U_{d r y}}{d t}=W_{d r y, s m} H_{d r y, s m}-W_{d r y, h u m} H_{d r y, h u m}+U A_{m}\left(T_{w}-T_{a i r}\right)-U A_{a}\left(T_{w}-T_{a m b}\right),
$$

\section{Vapour}

$$
\frac{m_{v}}{d t} U_{v}+m_{v} \frac{U_{v}}{d t}=W_{v, s m} H_{v, s m}+W_{i n j} H_{i n j}-W_{v, h u m} H_{v, h u m}+W_{i n j} \lambda+U A_{m}\left(T_{w}-T_{a i r}\right)-U A_{a}\left(T_{w}-T_{a m b}\right),
$$

where $U\left(\mathrm{~J} \mathrm{~kg}^{-1}\right)$ and $H\left(\mathrm{~J} \mathrm{~kg}^{-1}\right)$ are the internal energy and enthalpy of the gases respectively, and the heat capacity $C p$ of dry air and vapor is defined by [28]

$$
\frac{C p}{R}=A+B T+C T^{2}+D T^{-2}
$$

where, according to [28], the values of $C p_{d r y}\left(\mathrm{~J} \mathrm{~kg}^{-1} \mathrm{~K}^{-1}\right)$ between $273.15 \mathrm{~K}$ and $373.15 \mathrm{~K}$ are

$$
A=3.355, \quad B=0.575 \times 10^{-3}, \quad C=0, \quad D=-0.016 \times 10^{-5},
$$

and, according to [28], the values of $C p_{v}\left(\mathrm{~J} \mathrm{~kg}^{-1} \mathrm{~K}^{-1}\right)$ between $273.15 \mathrm{~K}$ and $373.15 \mathrm{~K}$ are

$$
A=3.47 \quad B=1.450 \times 10^{-3} \quad C=0 \quad D=0.121 \times 10^{-5},
$$

where the $C_{p v}$ of each gas component is:

$$
C v=C p-R
$$

All the model parameters are listed in Appendix. 


\subsection{Model summary}

After the physical study of the humidifier model, a summary of the various model variables is performed. The two control inputs are as follows:

$$
U=\left[\begin{array}{l}
U_{1} \\
U_{2}
\end{array}\right]=\left[\begin{array}{l}
W_{s m} \\
P w
\end{array}\right],
$$

where $P w\left(\mathrm{~J} \mathrm{~s}^{-1}\right)$ is the electric power of the resistor, being $(P w=V I)$. There are other input variables that affect the system, $R H_{a m b}$ and $T_{s m}(\mathrm{~K})$, but they cannot be manipulated, so they are considered as measurable exogenous disturbances. It should be clarified that the maximum electrical power supplied by the resistor is $1500 \mathrm{~W}$, while the maximum compressor air flow is $10 \mathrm{slpm}$. The system states are

$$
X=\left[\begin{array}{c}
\dot{x}_{1} \\
\dot{x}_{2} \\
\dot{x}_{3} \\
\dot{x}_{4}
\end{array}\right]=\left[\begin{array}{c}
m_{d r y} \\
m_{v} \\
T_{h u m} \\
T_{w}
\end{array}\right] .
$$

There are five lumped parameters used to tuned the final model according to the experimental results:

$$
\left[\begin{array}{c}
\operatorname{Pr}_{1} \\
\operatorname{Pr}_{2} \\
\operatorname{Pr}_{3} \\
\operatorname{Pr}_{4} \\
\operatorname{Pr}_{5}
\end{array}\right]=\left[\begin{array}{c}
m_{w} C p_{w} \\
U A_{m} \\
U A_{w} \\
U A_{a} \\
V_{h u m}
\end{array}\right]
$$

For furhter details regarding the experimental parameters and its relationship with the lumped parameters of equation 26, please refer to the Appendix of the manuscript. The software tools used for simulationg the proposed model are MATLAB ${ }^{\circledR}$ and Simulink ${ }^{\circledR}$. The real-time software that controls the humidifier and the complete fuel-cell test station was developed using LabVIEW ${ }^{\circledR}$. In general terms, it is composed of two computers (each with four cores i5 processor at $2.6 \mathrm{GHz}$ clock frequency): the host and the real-time operating system (RTOS). The host provides a LabVIEW ${ }^{\circledR}$ based development environment and the graphical user interface. It is responsible for the start up, shut down, configuration changes and control settings during operation. The RTOS implements the control algorithms and the data acquisition via a field-programmable gate array (FPGA), in order to have high speed data processing. Control, security and monitoring tasks are conducted by a CompactRIO (reconfigurable Input/Output) system from National Instruments. In order to record the analog sensor signals, a 32-channel 16-bit analog input module from National Instruments is used (NI-9205). A 8-channel, digital input/output (I/O) module generates the necessary transistortransistor logic (TTL) signals for different security and diagnostic tools. In the Appendix, Fig. 8 shows a sketch of the simulink interface, where the four states in (25) can be differentiated.

\section{Experimental validation}

\subsection{Test bench setup and scenarios}

A Cellkraft P-10 humidifier was used to validate the proposed modeling approach [29]. This is an active air humidifier especially suited for laboratory testing of fuel-cell systems. Its range of operation goes from 0 slpm to 10 slpm of air inflow, from 0 to 20 bar and $-20^{\circ} \mathrm{C}$ to $125^{\circ} \mathrm{C}$ of output pressure and output dew point respectively. Under this operating conditions, the humidifier can set the air outflow at different relative humidities, from $15 \%$ up to $95 \%$. Figure 2 shows the array of sensors used to perform the experiments presented along this section. Taking into account both system inputs, $P w$ and $W_{s m}$, three values for $P w$ and four values for $W_{s m}$ were selected in order to perform 12 representative validation tests. With these experiments, the distribution of data was enough to validate the analytical control-oriented model over the entire working range of the humidifier with a PEMFC (see Fig. 3). 


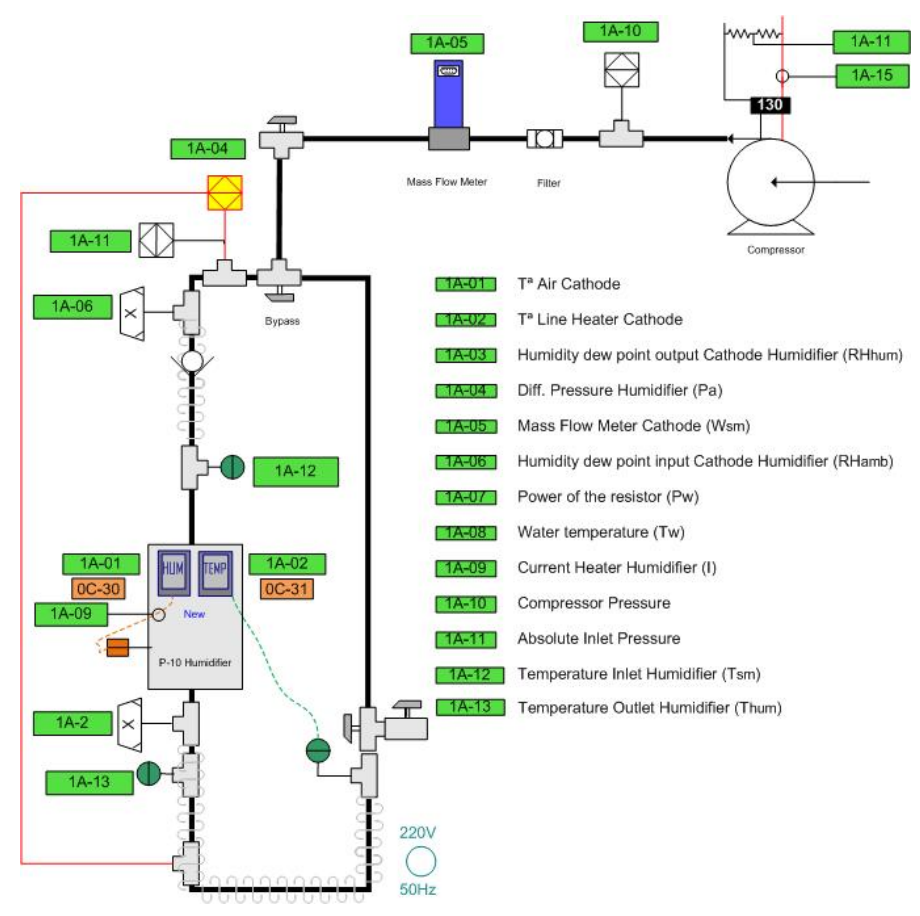

Figure 2. Schematic of sensors, humidifier and line heater

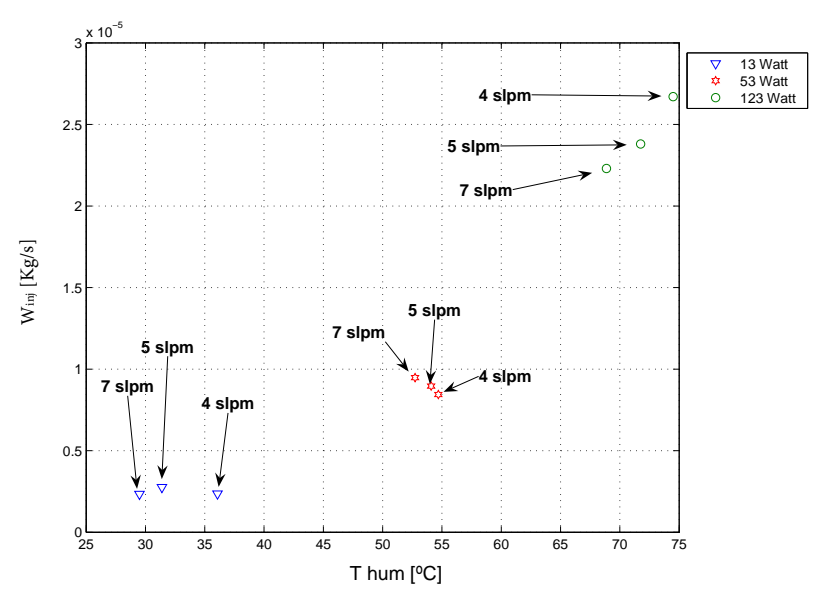

Figure 3. Vapour transport through the membrane

\subsection{Validation results}

As presented in previous sections, two system inputs are considered into the model $\left(P w\right.$ and $\left.W_{s m}\right)$, while three variables are considered as measurable outputs, the outlet air temperature $T_{\text {hum }}$, the air pressure $P_{\text {hum }}$ and the relative humidity of the humidifier outlet air $R H_{\text {hum }}$. In order to present the validation procedure, Figs 4,5 and 6 show a set of results of one of the 12 experiments. Steady-state conditions provided the necessary information to tune a set of parameters $\left(U A_{m}, U A_{w}\right.$ and $\left.U A_{a}\right)$, while the system dynamics provided the rest of information needed to complete the parameters tuning $\left(m_{w} C p_{w}\right)$. The entire set of experiments have been used to validate and make an ultimate tuning of the final model. The difference between the measurements of three outputs and the model remains below $5 \%$ for all the considered validation experiments. The first experiment, shown in Fig. 4, presents the dynamic behavior 


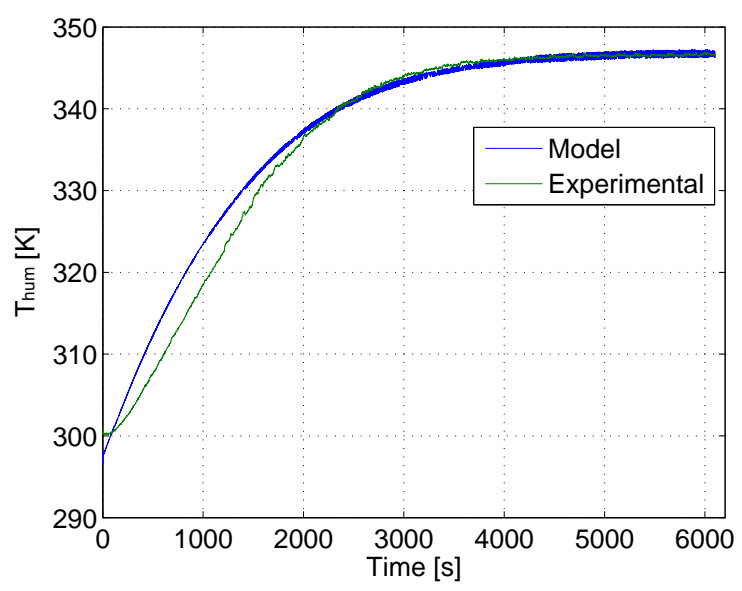

Figure 4. Power: $123 \mathrm{~W}$; Air mass flow: 5 slpm

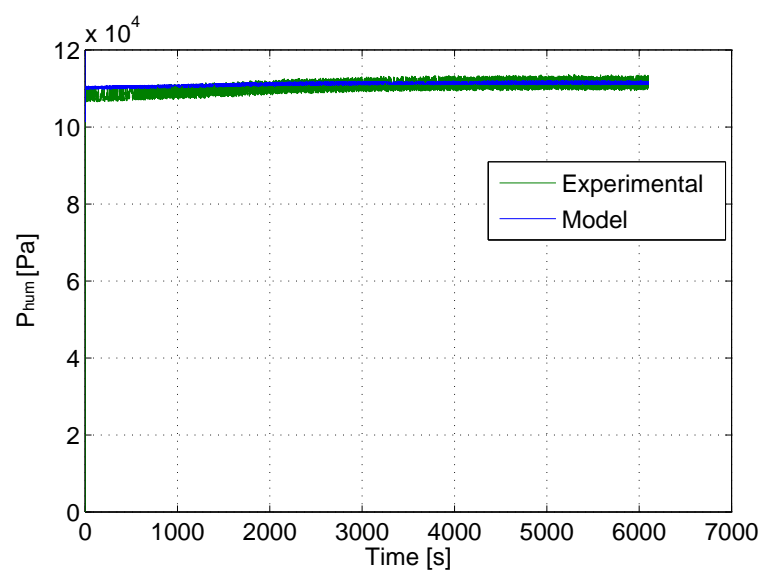

Figure 5. Power: $123 \mathrm{~W}$; Air mass flow: 5 slpm

of the variable $T_{\text {hum }}$ when a step in $P w$ is imposed (from $0 \mathrm{~W}$ to $123 \mathrm{~W}$ ) while $W_{s m}$ is kept constant in $5 \mathrm{slpm}$. In the same figure, both the experimental measurement and the modeled variable are compared, showing that the model uncertainty remains below $5 \%$.

For the same step input in $P w$, Fig. 5 presents the behaviour of the output air pressure $\left(P_{\text {hum }}\right)$. It can be noticed that the experimental test and the model variable have differences below 5\% during the entire test, for both the dynamical phase (0 to 3000s) and the steady state operation (3000s to 6000s).

In Fig. 6, the time evolution of the humidifier relative humidity $\left(R H_{h u m}\right)$ is presented for the same step in $P w$ (shown in Figs. 4 and 5). It is important to stress that humidity sensors have typically slow dynamics, so the model validation can only be done when steady-state conditions are reached, in this case after 3000s.

It is worth noticing that at temperatures $T_{\text {hum }}$ close to the operating point of fuel-cell stacks $\left(70^{\circ} \mathrm{C}\right.$ to $\left.80^{\circ} \mathrm{C}\right)$, the vapor injected to the air, and consequently the relative humidity, are very sensitive to changes in the flow rate (see Fig. 3 ). Therefore, in order to have a more accurate performance and stability of the overall system, a closed-loop control strategy should be implemented, so that a better regulation of the variables and robustness against uncertainties of the system is ensured. 


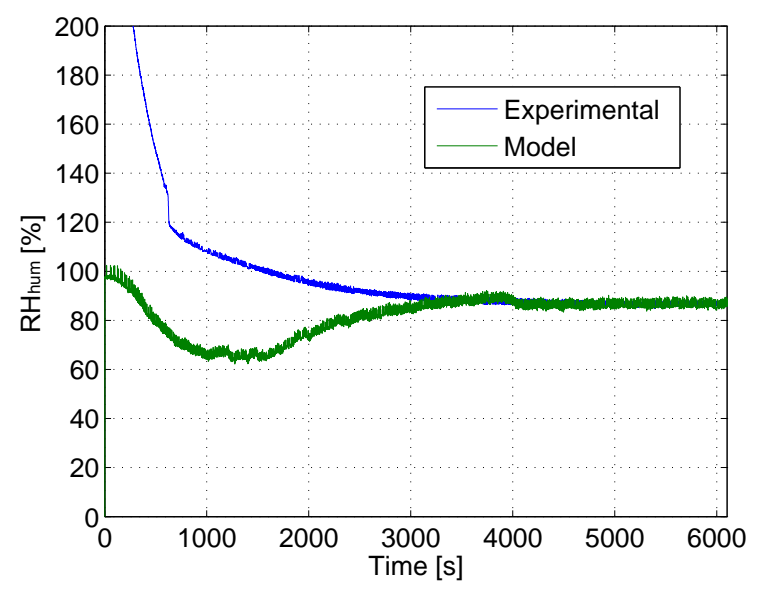

Figure 6. Power: $123 \mathrm{~W}$; Air mass flow: $5 \mathrm{slpm}$

\section{Control problem statement}

\subsection{Control objective and strategy design}

In order to show the usefulness of the proposed dynamical model for simulation and control tasks, this paper presents a controller design that uses the proposed model. To this end, the control objective is to robustly regulate the outlet $R H$ of the humidifier, manipulating the power $P w$.

As explained previously, the humidifier model is intrinsically a representation of a non-linear system. Therefore, to guaranty a robust regulation performance when considering internal and external perturbations, a variable structure controller can be designed and tested [30]. The selected controller is the so-called Super Twisting algorithm, which acts over the second derivative of the output, steering to zero the sliding variable in finite time [31]. In this case, the sliding variable $s(t)$ is the deviation of the output, i.e.,

$$
s(t)=R H_{r e f}(t)-R H(t) .
$$

Analysing (2c), it is concluded that $P_{v, \text { hum }}$ is linearly dependent on $m_{v, \text { hum }}\left(x_{2}\right)$ and $\dot{x}_{2}$ is a function of $\left(x_{1}, x_{2}, x_{3}, x_{4}\right)$. Then, due to the dependency of $\dot{x}_{3}$ on the control action, it can be readily proven that $s(t)$ have a relative degree of two with respect to the control input $u(t)$, i.e.,

$$
\left\{\begin{array}{l}
\frac{\partial s}{\partial u}=0 \\
\frac{\partial \dot{s}}{\partial u} \neq 0 .
\end{array} \quad \frac{\partial \ddot{s}}{\partial u} \neq 0\right.
$$

The Super Twisting algorithm was first conceived for systems with unitary relative degree. However, in this case a Super Twisting controller can be synthesized by approximating the remaining oscillation mode of $s(t)$ to zero. This method has been successfully validated and tested in simulation applying the concept of practical relative degree [32]. Then, the second derivative of $s(t)$ can be expressed as smooth functions of both the state variable and the control input, i.e.,

$$
\ddot{s}(x)=\phi(t, x, u)+\gamma(t, x) \dot{u},
$$

considering the following boundary conditions:

$$
\begin{gathered}
\phi \leq \Phi, \\
0<\Gamma_{\min }<\gamma<\Gamma_{\max } .
\end{gathered}
$$

There are several algorithms able to solve the stabilization problem expressed in (29) in a finite time by using the global limits expressed in (30). The control law of the Super Twisting algorithm uses two terms namely $u_{1}(t)$ and $u_{2}(t)$, and defined in [33] as 


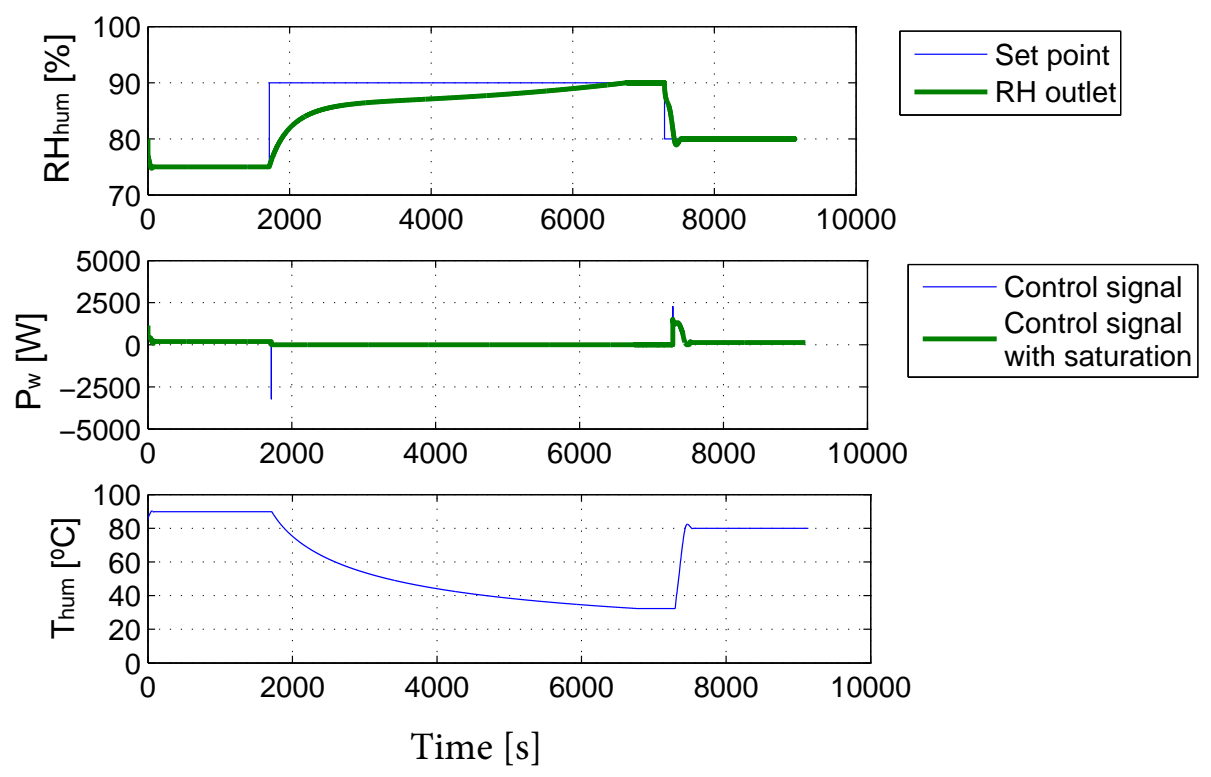

Figure 7. System variables under super-twisting control law.

$$
\begin{aligned}
& \dot{u_{1}}=-\Omega|s|^{0.5} \operatorname{sign}(s), \\
& u_{2}=-W \operatorname{sign}(s),
\end{aligned}
$$

while the conditions for finite-time convergence are

$$
\begin{aligned}
W & >\frac{\Phi}{\Gamma_{\min }}, \\
\Omega^{2} & =\frac{4 \Phi}{\Gamma_{\min }} \frac{\Gamma_{\max }(W+\Phi)}{\Gamma_{\min }(W-\Phi)} .
\end{aligned}
$$

Note that an integrator is included in the controller design in order to achieve the integral control action in (31a). Controller parameters for the proposed control design including the physical bounds of the system variables and satisfying (32) are $W=1$ and $\Omega=2$.

\subsection{Simulation results}

Figure 7 shows the dynamic behaviour of the variables $R H_{h u m}, P w$ and $T_{h u m}$ when the humidifier is under the non-linear control law (31a) and (31b). Note that $R H_{\text {hum }}$ can be fast decreased, but its increase is dynamically limited. This is because the control action is unbalanced, meaning that $P w$ can take positive values but not negative (the system can be forced heated but not cooled). For this reason, the time required to reach a step-up set point is greater than the time for a step-down reference regulation. Apart from this typical behavior, it is worth stressing that the supertwisting controller efficiently solves the regulation of the nonlinear system, shows promising results to be considered for real-time implementation due to its inherent robustness against uncertainties as shown in (30a) and (30b). Also the control law (31a) (31b) has a simple structure, reducing the computational effort of the controller.

\section{Conclusion}

A control oriented fourth-order non-linear model of an air humidifier was developed and validated through experimental tests. The sub-system is a key component in fuel-cell applications and its dynamic behavior affects the 
fuel-cell performance, stability and durability. The modeling approach is presented in a methodological way, thus future readers can find a straightforward way to model similar systems, even with other scaling factors and operating conditions. The model was experimentally validated under both static and dynamic conditions, covering the entire range of operation of the humidifier in a typical fuel-cell operation. Notice that the vapor injected to the air is one of the most important variables of the model, and that it is mostly dependent on the liquid water temperature. These dynamics have been also validated experimentally. The complete model schematics in Simulink and its set of parameters are openly provided for further simulation, control and estimation developments. Finally, in order to show the suitability and usefulness of the approach, the model was used as base of design for a non-linear control strategy based on second order sliding modes.

\section{Acknowledgment}

The tests were performed at the Fuel Cells Laboratory of the Institut de Robòtica i Informàtica Industrial (CSICUPC) and were only possible due to its advanced equipment and proficient technical staff.

\section{Auxiliary functions and parameters}

$$
\begin{aligned}
\dot{x}_{1}= & \left(U_{1}-\operatorname{Pr}_{2}\left(x_{1}-x_{2}\right)-A_{2} A_{3}-\operatorname{Pr}_{3}\left(T_{w}-T_{a m b}\right)\right) P r_{1}{ }^{-1} \\
\dot{x}_{2}= & \left(A_{4} C p_{a}\left(T_{s m}-T_{a m b}\right)-A_{5} C p_{v}\left(T_{s m}-T_{a m b}\right)-\left(A_{6}+A_{7}-P_{c a}\right) b_{4}\left(1+\frac{G_{v}}{G_{a}} \frac{P_{d r y, h u m}}{P_{v, h u m}}\right)^{-1}\right. \\
& C p_{a}\left(x_{2}-T_{a m b}\right)-\left(A_{6}+A_{7}-P_{c a}\right) b_{4}-\left(A_{6}+A_{7}-P_{c a}\right) b_{4}\left(1+\frac{G_{v}}{G_{a}} \frac{P_{d r y, h u m}}{P_{v, h u m}}\right)^{-1} \\
& \left.C p_{v}\left(x_{2}-T_{a m b}\right)+A_{2} A_{3}+\operatorname{Pr}_{1}\left(x_{1}-x_{2}\right)-\operatorname{Pr}_{4}\left(x_{2}-T_{a m b}\right)\right)\left(\left(x_{3} C p_{a}\right)+\left(x_{4} C p_{v}\right)\right)^{-1} \\
\dot{x}_{3}= & A_{4}-\left(A_{6}+A_{7}-P_{c a}\right) b_{4}\left(1+\frac{G_{v}}{G_{a}} \frac{P_{d r y h u m}}{P_{v h u m}}\right)^{-1} \\
\dot{x}_{4}= & A_{5}+A_{2} A_{3}-\left(A_{6}+A_{7}\right) b_{4}-\left(A_{6}+A_{7}-P_{c a}\right) b_{4}\left(1+\frac{G_{v}}{G_{a}} \frac{P_{d r y h u m}}{P_{v h u m}}\right)^{-1}
\end{aligned}
$$

$$
\begin{aligned}
A_{1}= & \frac{x_{4} x_{2} R_{c}}{V_{h u m} G_{v}} 101325\left(10^{5.115664 \frac{1687.537}{\left(x_{2}-273\right)+230.170}} 101325\right)^{-1} \\
A_{2}= & 10^{-6}\left(3-1.67\left(0.04+17.81 b_{1}-39.85 b_{1}^{2}+36 b_{1}^{3}\right)\right) \\
& e^{11378\left(T_{s m}^{-1}-x_{2}^{-1}\right)}\left(21.06-17.81 A_{1}+39.85 A_{1}^{2}-36 A_{1}^{3}\right) b_{2} b_{3} \\
A_{3}= & \left(-2438 x_{2}+3167329.84\right) \\
A_{4}= & U_{1}\left(1+\frac{G_{v}}{G_{a}} P_{\text {vamb }}\left(\frac{U_{1} T_{\text {sm }} R_{c}}{V_{\text {hum }} G_{a}}\right)^{-1}\right)^{-1} \\
A_{5}= & U_{1}-A_{4} \\
A_{6}= & x_{3} x_{2} R_{c} /\left(V_{\text {hum }} G_{a}\right) \\
A_{7}= & \left(x_{4} x_{2} R_{c} /\left(V_{\text {hum }} G_{v}\right)\right.
\end{aligned}
$$




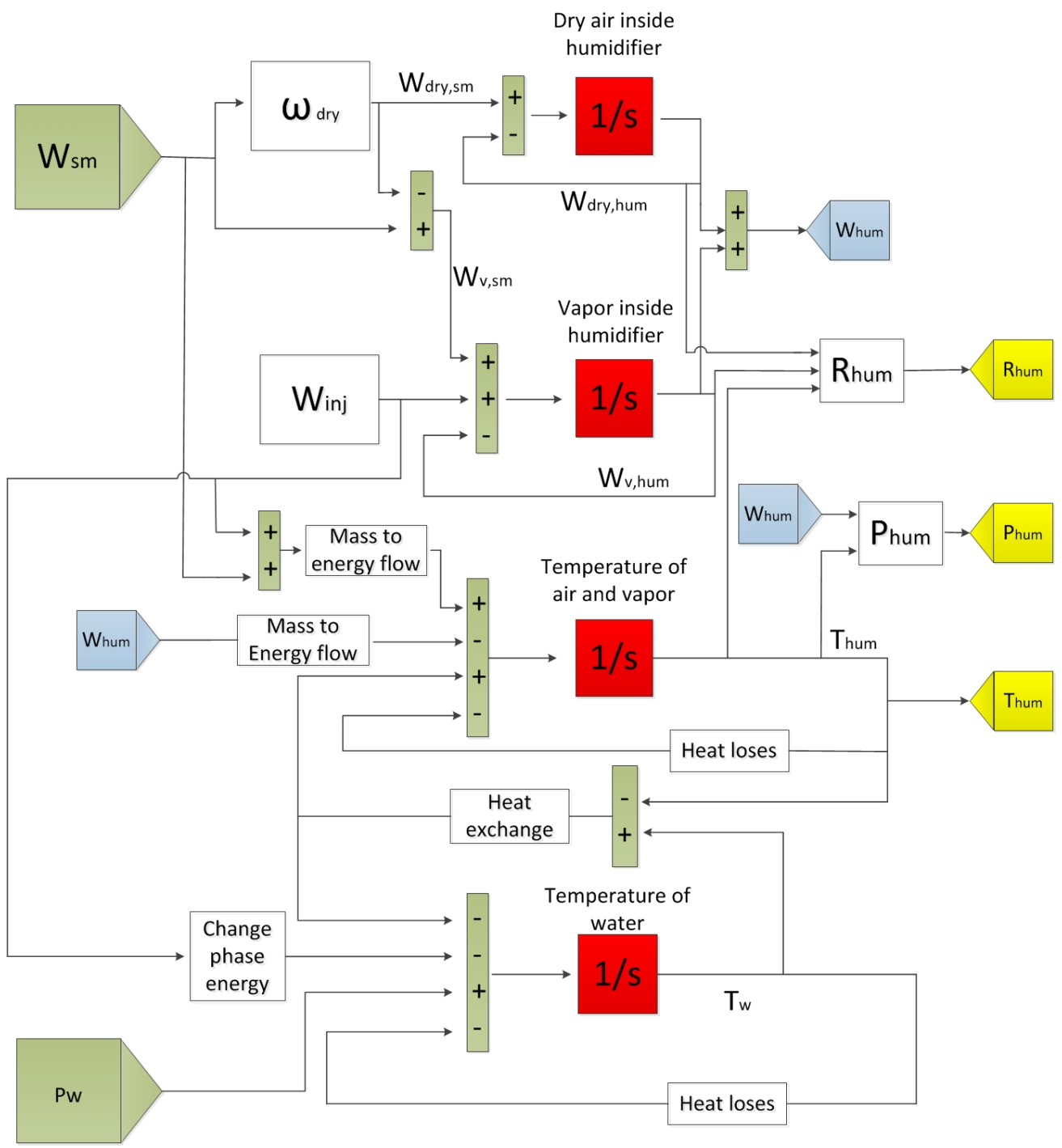

Figure 8. Drawing of the Simulink interface developed in this study

\begin{tabular}{|l|}
\hline State space auxiliary functions \\
\hline$b_{1}=\left(R H_{a m b}+1\right) / 2$ \\
$b_{2}=0.04$ \\
$b_{3}=S_{a}-S_{w}=22-4.15=17.85$ \\
$b_{4}=\rho_{a} /\left(5.1724 \times 10^{7}\right)$ \\
\hline
\end{tabular}


General physical constants

\begin{tabular}{|c|c|}
\hline Parameter & Value \\
\hline & \\
Air density $\left(\rho_{a}\right)$ & $1.29 \mathrm{l} / \mathrm{g}$ \\
Air molar mass $\left(G_{a}\right)$ & $0.029 \mathrm{~kg} / \mathrm{mol}$ \\
Vapor molar mass $\left(G_{v}\right)$ & $0.018 \mathrm{~kg} / \mathrm{mol}$ \\
Ideal Air gas constant $\left(R_{a}\right)$ & $286.9 \mathrm{~J} /(\mathrm{kg} \mathrm{K})$ \\
Ideal Vapor gas constant $\left(R_{v}\right)$ & $461.5 \mathrm{~J} /(\mathrm{kg} \mathrm{K})$ \\
Ideal constant gas $\left(R_{c}\right)$ & $0.082 \mathrm{~atm} \mathrm{l} /(\mathrm{mol} \mathrm{K})$ \\
\hline
\end{tabular}

\begin{tabular}{|c|c|}
\hline Operatingconditions & Value \\
\hline & \\
Ambient temperature $\left(T_{a m b}\right)$ & $298 \mathrm{~K}$ \\
Supply manifold temperature $\left(T_{s m}\right)$ & $303 \mathrm{~K}$ \\
Ambient relative humidity $\left(R H_{a m b}\right)$ & $60 \%$ \\
Ambient air pressure $\left(P_{a m b}\right)$ & $101325 \mathrm{~Pa}$ \\
\hline
\end{tabular}

\begin{tabular}{|c|c|}
\hline Experimental parameters & Value \\
\hline & \\
Water mass and heat capacity $\left(P r_{1}\right)$ & $2.5 \mathrm{~J} / \mathrm{K}$ \\
Membrane heat coef. transfer. $\left(P r_{2}\right)$ & $3 \mathrm{~J} / \mathrm{K}$ \\
Water heat coef. transfer. $\left(P r_{3}\right)$ & $0.02 \mathrm{~J} / \mathrm{K}$ \\
Air heat coef. transfer. $\left(P r_{4}\right)$ & $0.2 \mathrm{~J} / \mathrm{K}$ \\
Volum $\left(P r_{5}\right)$ & 0.21 \\
\hline
\end{tabular}

\section{References}

[1] F. Migliardini, O. Veneri, P. Corbo "Management issues of direct hydrogen Fuel Cell Systems for application in automotive field". Electrical Systems for Aircraft, Railway and Ship Propulsion (ESARS), 2012, pp. 1-6.

[2] J.M. Andjar, F. Segura, "Fuel cells: History and updating. A walk along two centuries", Renewable and Sustainable Energy Reviews, 13 (9), 2009 pp. $2309-2322$

[3] T.V. Nguyen, R.E. White, A. Water. "A water and heat management model for proton-exchange-membrane fuel cells", Journal of Electrochemical Society 140, 1993, pp. 2178-2186.

[4] N. Fouquet, C. Doulet, C. Nouillant, G. Dauphin-Tanguy, B. Ould-Bouamama. "Model based PEM fuel cell state-of-health monitoring via ac impedance measurements", Journal of Power Sources, 159, 2006, pp. 905-913.

[5] A. Thomas Zawodzinski Jr., T. E. Springer, F. Uribe, S. Gottesfeld. "Characterization of polymer electrolytes for fuel cell applications". Solid state Ionics, 60, 1993, pp. 199-211.

[6] D.H. Jeon, K.N. Kim, S.M. Baek, J.H. Nam, "The effect of relative humidity of the cathode on the performance and the uniformity of PEM fuel cells", International Journal of Hydrogen Energy, 36 (19), 2011, pp. 12499-12511.

[7] E. Breaz, F. Gao, B. Blunier, R. Tirnovan. "Mathematical modeling of proton exchange membrane fuel cell with integrated humidifier for mobile applications", IEEE Transportation Electrification Conference and Expo (ITEC 12), Dearborn, USA, 2012, ISBN 978-1-4673-1406-0, pp. 1-6.

[8] H. Junming, X. Liangfei, L. Jianqiu, M. Ouyang, C. Siliang, F.Chuan. "Water management in a self-humidifying PEM fuel cell system by exhaust gas recirculation”. Transportation Electrification Asia-Pacific (ITEC Asia-Pacific), 2014, ISBN 978-1-4799-4240-4, pp 1-6.

[9] B.J. Kim, M.S. Kim. "Studies on the cathode humidification by exhaust gas recirculation for PEM fuel cell". Int J Hydrogen Energy, 37 2012, pp. 42904299.

[10] Z.M. Wan, J.H. Wan, J. Liu, Z.K. Tu, M. Pan, Z.C. Liu. "Water recovery and air humidification by condensing the moisture in the outlet gas of a proton exchange membrane fuel cell stack". Appl Therm Eng, 42 2012, pp. 173178.

[11] N.B. Houreh, E. Afshari. "Three-dimensional CFD modeling of a planar membrane humidifier for PEM fuel cell systems". Int J Hydrogen Energy, 9 2014, pp. 1496914979.

[12] E. Afshari, N. Baharlou Houreh. "Performance analysis of a membrane humidifier containing porous metal foam as flow distributor in a PEM fuel cell system". Energy Convers Manage, 88 2014, pp. 612621.

[13] E. Afshari, N. Baharlou Houreh. "Two dimensional numerical modeling of a membrane humidifier with porous media flow field for PEM fuel cell". Internation journal of modern physics C, 26, 6, 2015.

[14] G. Vasu, A.K. Tangirala, B. Viswanathan, K.S. Dhathathreyan, "Continous bubble humidification and control of relative humidity of $\mathrm{H}_{2}$ for a PEMFC system", International Journal of Hydrogen Energy, 33, 2008, pp. 4640-4648.

[15] S. H. Hwang, M. S. Kim, "An experimental study on the cathode humidification and evaporative cooling of polymer electrolyte membrane fuel cells using direct water injection method at high current densities", Applied Thermal Engineering, 2016, DOI:http://dx.doi.org/doi: 10.1016/j.applthermaleng.2016.01.091. 
[16] L. Xingsheng, M. Shihu, Z. Juntao, Z. Hong, Z. Weilin, Z. Yangjun. "Comparative Study of Membrane Humidifier and Enthalpy Wheel Humidifier for Large Power Fuel Cell System”.J. Fuel Cell Sci. Technol 6(1), 014501 , 2008.

[17] Ahluwalia, R.K., Wang, X., Johnson, W.B., Berg, F., Kadylak, D., "Performance of a cross-flow humidifier with a high flux water vapor transport membrane".Journal of Power Sources, Volume 291, 2015, pp. 225-238.

[18] D. Kadylak, W. Merida. "Experimental verification of a membrane humidifier model based on the effectiveness method".J Power Sources, 195, 2010, pp. 31663175.

[19] P. Cave, W. Merida. "Water flux in membrane fuel cell humidifiers, flow rate and channel location, effects". J Power Sources, 175, 2008, pp. 408418.

[20] K. Park, Y. Choe, S. Choi, "Dynamic modeling and analysis of a shell-and-tube type gas-to-gas membrane humidifier for Polymer Electrolyte Membrane Fuel Cell applications", International journal of hydrogen energy, 33, 2008, pp. 2273-2282.

[21] D. Chen, H. Peng. "A Thermodynamic Model of Membrane Humidifiers for PEM Fuel Cell Humidification Control", J. Dyn. Sys., Meas., Control 127(3), 2005, 424-432.

[22] D. Chen, H. Peng. "Analysis of non-minimum phase behavior of PEM fuel cell membrane humidification systems", American Control Conference, 2005,E-ESBN 0-7803-9099-7, pp. 3853-3858.

[23] D. Chen, W. Li, H. Peng. "An experimental study and model validation of a membrane humidifier for PEM fuel cell humidification control" Journal of Power Sources, 180, 2008, pp. 461-467.

[24] K. Sanggyu, M. Kyoungdoug and Y. Sangseok, "Two dimensional dynamic modeling of a shell-and-tube water-to-gas membrane fuel cell", International Journal of Hydrogen energy, 35, 2009, pp. 1727-1741.

[25] D. A. McKay, A. G. Stefanopoulou, J. Cook, "Model and experimental validation of a controllable membrane-type humidifier for fuel cell applications", American Control Conference, 2008, E-ISBN 978-1-4244-2079-7, pp.312-317.

[26] A.Z.Weber, J. Newman, “Transport in polymer-electrolyte membranes I. Physical model”, Journal of The Electrochemical Society, 150, 2003, pp. 1008-1015.

[27] T.E. Springer, T.A. Zawodzinski, S. Gottesfeld. "Polymer electrolyte fuel cell model", Journal of Electrochemical Society, 138, 1991, pp. 2334-2342.

[28] Y. Demirel. "Non-equilibrium Thermodynamics. Transport and Rate Processes in Physical, Chemical and Biological Systems, Second edition 2007.

[29] "Cellkraft P-10 Specifications document”. http://www.cellkraft.se/downloads/P-Series.pdf.

[30] C. Kunusch, P.F. Puleston, M.A. Mayosky, A. Husar. "Control oriented Modeling and Experimental validation of a PEMFC Generation System”, Energy Conversion, IEEE Transactions on, 2011, 26, pp 851-861.

[31] A. Levant. "Sliding order and sliding accuracy in sliding mode control", International Journal of Control, 1993, 58, 1247-1263.

[32] A.G.G. Hernandez, L Fridman, A Levant, Y Shtessel, R Leder, CR Monsalve, "High-order sliding-mode control for blood glucose: Practical relative degree approach", Control Engineering Practice 21 (5), 2013, 747-758.

[33] L. Fridman and A. Levant. "Sliding mode control in engineering”, chapter 3: Higher order sliding modes, Marcel Dekker, 2002 , pp. 53-101. 